\title{
Nonpharmacological Management of Dementia: A Review
}

\author{
Pragya Lodha ${ }^{1}$, Avinash Desousa ${ }^{2}$
}

\begin{abstract}
Dementia is a complex neuropsychiatric disorder that needs medical and nonpharmacological approaches for its long-term management. This review aims at providing an overview of the various nonpharmacological strategies employed in the long-term management of dementia. The paper looks at various treatment approaches like occupational therapy, methods to improve daily living, alternative medicine approaches, and various innovative approaches like animal-assisted and pet therapy. The paper also outlines various forms of psychotherapy and cognitive enhancement methods that may be used for patients and their caregivers alike. Certain general guidelines for the nonpharmacological management of dementia at home are suggested, which shall enhance the quality of life of patients with dementia.

Keywords: Dementia, Home-based management, Nonpharmacological management, Occupational therapy, Psychotherapy.

Indian Journal of Private Psychiatry (2019): 10.5005/jp-journals-10067-0038
\end{abstract}

\section{INTRODUCTION}

There are 50 million suffering from dementia and India houses the second most number of them with an estimated 4.1 million people as per the "Dementia India" report published by the Alzheimer's and Related Disorders Society of India. This is expected to double by $2035 .{ }^{1}$ The onset of dementia is usually seen in 60 s and increases when individual reaches in the octogenarian age. Dementia, a common and neuropsychiatric syndrome, in itself is not a specific disease/disorder. It refers to a group of symptoms caused by brain disorders. ${ }^{2}$ It is a progressive condition that affects the abilities to think, solve problems, or control emotions that brings about cognitive and personality changes with functional decline. ${ }^{3}$ Dementia may also lead to progressive memory loss. Activities of daily living (ADLs) are progressively impaired in dementia. ${ }^{4}$ Biological functions such as sleep and appetite are usually affected by dementia, as are neuromuscular functions such as gait and balance. ${ }^{5}$

Though nonpharmacological treatment (NPT) is the first line of treatment for dementia, by choice, treatment has persisted to remain pharmacological in approach. Reasons such as less investment in cost of human labor and time and quicker administration of medication have served a win over nonpharmacological management. ${ }^{6}$ The development of new drugs and their availability has received considerable attention from the media, the public, professionals, and family caregivers as well as from persons with dementia. ${ }^{7}$ However, for over a decade, research has favored the nonpharmacological interventions for management of dementia as the first line of treatment as they have been scientifically addressed and evidence of their effectiveness has been systematized. ${ }^{8}$

\section{Nonpharmacological Management of Dementia}

In an ideal scenario, dementia should be diagnosed followed by postdiagnostic counseling to provide support with coming to terms with the diagnosis. The aim of rehabilitation in dementia is to improve functioning of the individual through a holistic approach that involves psychosocial, cognitive, physical, and sensory components. ${ }^{9}$ These strategies may be implemented in a variety of settings and treatment modalities. A range of psychosocial
${ }^{1}$ Department of Psychiatry, De Sousa Foundation, Mumbai, Maharashtra, India

${ }^{2}$ Department of Psychiatry, Lokmanya Tilak Municipal General Hospital and Lokmanya Tilak Medical College, Mumbai, Maharashtra, India

Corresponding Author: Avinash Desousa, Department of Psychiatry, Lokmanya Tilak Municipal General Hospital and Lokmanya Tilak Medical College, Mumbai, Maharashtra, India, Phone: +91 9820696828, e-mail: avinashdes888@gmail.com

How to cite this article: Lodha P, Desousa A. Nonpharmacological Management of Dementia: A Review. Ind J Priv Psychiatry 2019; 13(2):62-70.

Source of support: Nil

Conflict of interest: None

interventions that are flexible should be developed to match the needs of the patient and the caregiver.

Cognitive problems have been the traditional focus of interest in research and management for people with dementia. ${ }^{10}$ However, present research findings have revealed a number of commonly seen noncognitive symptoms (it is important to note that there is an ongoing debate regarding the basic terminology for "noncognitive" symptoms. The term currently favored in the psychiatric literature is "behavioral and psychological symptoms of dementia," but most of the psychology community still uses the label "challenging behavior." Researchers have distinguished between behavioral excesses and behavioral deficits) ${ }^{11}$ that are problematic not only for the person but also for their caregivers; thus, they are relevant in relation to clinical management. The noncognitive symptoms include agitation, aggression, mood disorders and psychosis, sexual disinhibition, eating problems, and abnormal vocalizations. ${ }^{12}$ The International Psychogeriatric Association grouped these symptoms together under an umbrella term "behavioral and psychological symptoms of dementia," abbreviated as BPSD. ${ }^{13}$ Behavioral and psychological symptoms of dementia are usually transient and often respond to simple changes in the environment or removal of aggravating factors. Behavioral and psychological symptoms of dementia involves pharmacological and nonpharmacological interventions, though a sound clinical background must identify the root cause of BPSD. ${ }^{14}$

The concerning switch from pharmacological to nonpharmacological management was born out of documented research,

() The Author(s). 2019 Open Access This article is distributed under the terms of the Creative Commons Attribution 4.0 International License (https://creativecommons. org/licenses/by-nc/4.0/), which permits unrestricted use, distribution, and non-commercial reproduction in any medium, provided you give appropriate credit to the original author(s) and the source, provide a link to the Creative Commons license, and indicate if changes were made. The Creative Commons Public Domain Dedication waiver (http://creativecommons.org/publicdomain/zero/1.0/) applies to the data made available in this article, unless otherwise stated. 
which outlined the substantial adverse effects like sedation, falls, extrapyramidal signs, and possibility of reduction in quality of life and possible accelerating cognitive decline in the patients. ${ }^{15}$ Though there exists no direct comparison to evidence the comparative use of pharmacological and NPT methods, the latter has shown to be beneficial in managing behavioral and psychological symptoms related to dementia. ${ }^{16}$ It has been reported that psychosocial interventions work best to reduce agitation and to improve other behavioral disturbances in people with dementia when they are personalized to reflect the individual's background and environmental circumstances. ${ }^{17}$

According to Cohen-Mansfield, most professionals have some training in medication prescription for BPSD but are not appropriately instructed about nonpharmacological interventions or receive information about their effectiveness. As a consequence, antipsychotics drugs are frequently prescribed before alternative nonpharmacological approaches are attempted, and patients are maintained in medication for long periods, which leads to increasing morbidity and mortality. Fewer side effects have been associated with NPTs, which render them as safer line of treatment. ${ }^{18}$

Nonpharmacological treatments entail a broad spectrum of approaches that involve to work with the patient and/or their caregivers, physical, and social environments-entailing psychological, psychosocial, interpersonal, behavioral, emotional, exercise, and environmental interventions. ${ }^{19}$ The NPTs can be broadly categorized as generalized (behavior nonspecific) or targeted (behavior-specific) treatments. These approaches either directly involve the patients and/or work through another agent-usually, the care provider or physical environment. ${ }^{20}$ These approaches conceptualize behavioral symptoms in three ways viz. the following: ${ }^{21}$

- As expressions of unmet needs (e.g., repetitive vocalizations for auditory stimulation).

- Inadvertently reinforced behavior in response to environmental triggers (e.g., patient learns screaming attracts increased attention).

- Consequences of a mismatch between the environment and patients' abilities to process and act upon cues, expectations, and demands.

These approaches generally work to modify patient and/ or caregiver cognition styles, behavior patterns, environments, precipitating events, or instructing in compensatory strategy use-to reduce the risk/vulnerability of the patients and to their environment. It is widely accepted that the care environment (physical and social) and day-to-day interactions between caregivers and persons with dementia can have a considerable impact. This means that virtually all dementia care has the potential to be therapeutic. ${ }^{22}$

Nonpharmacological alternatives encompass psychotherapy, psychoeducation, and self-care. Within that, it includes a wide range of therapies such as behavior therapy, reality orientation, music therapy, validation, and the potential of interesting new alternative options such as cognitive therapy, aromatherapy, and multisensory therapies. It is crucial to know that no one therapy is used in isolation but there are several overlaps between the therapies, and thus, an eclectic approach is the best to use. ${ }^{23}$

\section{Goals of Nonpharmacological Treatments}

It is crucial to consider that though NPTs are not to cure dementia in an individual but to help create effective changes that aid the management of the syndrome progression by the following: ${ }^{24,25}$
- Through improving the person's cognition in areas such as memory, concentration, language skills, or reasoning that usually come along with an effect on the person's performance in real-life situations or an associated improvement in the person's well-being, self-esteem, mood, and behavior.

- Through improving the person's ability to function in reallife, everyday situations, helping to maintain the person's independence for as long as possible. These are seen in cases ranging from mild to severe forms of dementia.

- Through the reduction of distress and mood disturbances in the person with dementia, by reducing depression and anxiety or by increasing adjustment or coping in the early stages of dementia.

- Through enhancing the person's quality of life with quality care and adequate psychosocial support.

- Through positive changes in the caregiver; these can include reduced depression, distress, or anxiety; reduced burden; increased coping skills; less distress regarding difficult behaviors; improved understanding and support from family and friends; and enhanced quality of life.

- Through changes in disturbing and distressing behaviors, such as aggression, inappropriate sexual behavior, or restlessness. Depending on the behavior and the factors contributing to it, the goal may be to reduce the frequency of the behavior, or its severity; where the behavior does not appear to be causing problems for the person with dementia, the goal may be to reduce the impact of the behavior on others, including family caregivers or care workers.

\section{Types of Nonpharmacological Treatments}

One way of categorizing the nonpharmacological methods of managing dementia can be categorizing them on the basis of nature of symptoms, which would appear like the following: ${ }^{26}$

- Cognitive/emotion-oriented interventions

- Reminiscence therapy

- Simulated presence therapy (SPT)

- Validation therapy

- Sensory stimulation interventions

- Acupuncture

- Aromatherapy

- Light therapy

- Massage/touch

- Music therapy

- Snoezelen multisensory stimulation

- Transcutaneous electrical nerve stimulation (TENS)

- Behavior management techniques (BMT)

- Other psychosocial interventions

- Animal-assisted therapy

- Exercise

\section{Role of Psychotherapies in Dementia Management}

\section{Behavioral Therapy}

It requires a period of detailed assessment in which the triggers, behaviors, and reinforcers also known as the ABC: antecedents, behaviors, and consequences are identified and their relationships are made clear to the patient. The principles of conditioning and learning theory are aimed at suppressing or eliminating challenging behaviors. More recently, positive programming 
methodologies have used nonaversive methods in helping to develop more functional behaviors. Overall, BMT include a wide variety of behavioral interventions such as functional analysis of specific behaviors, token economies, habit training, progressive muscle relaxation, communication training, behavioral or cognitivebehavioral therapy, and various types of individualized behavioral reinforcement strategies. ${ }^{27,28}$

\section{Reality Orientation Therapy}

It is one of the most widely used management strategies for working with people having dementia. It aims to help people with memory loss and disorientation by reminding them of facts about themselves and their environment. People with memory loss are oriented to their environment using a range of materials and activities. This involves consistent use of orientation devices such as signposts, notices, and other memory aids. Though, the efficacy of the therapy is debatable. ${ }^{29,30}$

\section{Validation Therapy}

Some of the features associated with dementia such as repetition and retreating into the past were in fact active strategies on the part of the affected individual to avoid stress, boredom, and loneliness. Validation therapists therefore attempt to communicate with individuals with dementia by empathizing with the feelings and meanings hidden behind their confused speech and behavior. It is the emotional content of what is being said that is more important than the person's orientation to the present. ${ }^{31,32}$

\section{Reminiscence Therapy}

This involves helping a person with dementia to relive past experiences, especially those that might be positive and personally significant, for example, family holidays and weddings. This therapy can be used with groups or with individuals. Group sessions tend to use activities such as art, music, and artifacts to provide stimulation. It is seen as a way of increasing levels of well-being and providing pleasure and cognitive stimulation. ${ }^{33,34}$

\section{Alternative Medicine Therapies for Dementia}

\section{Music Therapy}

It may involve engagement in a musical activity (e.g., singing or playing an instrument), or merely listening to songs or music. More recently, it has been found that there is a significant reduction in agitation in people with dementia who were played an individualized program of music as opposed to traditional relaxation music. Individuals with dementia may retain the ability to sing old songs, and musical abilities appear to be preserved in some individuals despite aphasia and memory loss. Music interventions range from activities administered by a professional music therapist to the presentation of recorded music by caregivers to patients in an individual or group setting. ${ }^{35-37}$

\section{Art-based Therapy}

It is a recommended treatment for people with dementia as it has the potential to provide meaningful stimulation, improve social interaction, and improve levels of self-esteem. Activities such as drawing and painting are thought to provide individuals with the opportunity for self-expression and the chance to exercise some choice in terms of the colors and themes of their creations. $^{38,39}$

\section{Activity Therapy}

This involves a diverse group of recreations such as dance, sport, and drama. It has been shown that physical exercise can have a number of health benefits for people with dementia. Dance therapy, with specific dance forms/moves, involves no prescriptive steps or motions but allows the participants to engage with each other in interactive movements. It is relevant to note that this may also fulfill a need for nonsexual physical contact which many people with dementia find soothing. ${ }^{40,41}$

\section{Complementary Therapies}

A number of different therapies like massage, reflexology, Reiki, therapeutic healing, herbal medicine, and aromatherapy are also employed. In terms of effectiveness, more careful consideration is needed. In general, most of the complementary therapies have not received a great deal of empirical investigation. ${ }^{42,43}$

\section{Acupuncture}

Acupuncture is an ancient Chinese treatment that has been used for over 3,000 years. Controlled investigations reveal that acupuncture outperforms drug therapy for the treatment of vascular dementia. Acupuncture was found both safe and effective; however, specific acupuncture protocols were found superior to conventional treatments. Multiple studies indicate that the microacupuncture system termed scalp acupuncture is particularly beneficial to vascular dementia patients. In vascular dementia, impaired blood flow deprives oxygen and nutrients to the brain; mental deterioration affects cognition, memory, language skills, emotions, and personality. The researchers cite Traditional Chinese Medicine (TCM) theory as the basis for their acupuncture protocol development. ${ }^{44,45}$

\section{Aromatherapy}

It is one of the fastest growing of all the complementary therapies. Aromatherapy consists of the use of fragrant oils from plants and has been used to promote sleep and reduce behavioral symptoms in individuals with dementia. It appears to have several advantages over the pharmacological treatments widely used for dementia. It has a positive image and its use aids interaction while providing a sensory experience. The two main essential oils used in aromatherapy for dementia are extracted from lavender and Melissa balm. There is an added advantage that there are several routes of administration such as inhalation, bathing, massage, and topical application in a cream. ${ }^{46}$

\section{Bright-light Therapy}

It has been increasingly used in an attempt to improve fluctuations in diurnal rhythms that may account for night-time disturbances and "sundown syndrome" (recurring confusion or agitation in the late afternoon or early evening) in people with dementia. Few controlled trials have been published with some evidence for improving restlessness and with particular benefit for sleep disturbances. Light stimulation also aims to improve the circadian disturbances in the sleep-wake cycles experienced by individuals with dementia. ${ }^{47}$

\section{Sensory Stimulation Therapies for Dementia}

\section{Multisensory Approaches}

This involves using a room designed to provide several types of sensory stimulation such as light, texture, smell, and sound. The 
use of these resources is tailored to the individual and not all of the available forms of stimulation may be used in one session. ${ }^{48}$

\section{Simulated Presence Therapy}

Simulated presence therapy involves video or audiotape recordings of family members that are played to the person with dementia. The content of the recordings may vary depending on the interests of the individual and may include conversations, stories, or shared memories. The intention is that the recorded voice of a family member is reassuring, and that anxiety and distress are reduced by making the environment of the person with dementia as familiar as possible. Overall, well-conducted studies are lacking, the evidence that SPT reduces behavioral symptoms of dementia is inconsistent, and SPT may have adverse effects in some patients. Simulated presence therapy is sometimes referred to as simulated family presence therapy because it originated from the observation that nursing home residents who received more visits from family members were less agitated and had greater life satisfaction. ${ }^{49,50}$

\section{Snoezelen Multisensory Stimulation Therapy}

Multisensory stimulation (MSS), otherwise known as Snoezelen therapy, combines the therapeutic use of light, tactile surfaces, music, and aroma. Multisensory stimulation is based on the premise that neuropsychiatric symptoms may result from periods of sensory deprivation. $^{51}$

\section{Transcutaneous Electrical Nerve Stimulation}

Transcutaneous electrical nerve stimulation is a noninvasive analgesic technique that is most often used for pain control and occasionally for neurological and psychiatric conditions, such as drug/alcohol dependency, headaches, and depression. Although some short-lived improvements in neuropsychological symptoms of dementia have been observed with TENS, definite conclusion on the possible benefits of this intervention cannot be made. ${ }^{52}$

\section{Physiotherapy and Exercise for Dementia Physical Exercises}

It has been shown that physical exercise can have a number of health benefits for people with dementia though research findings have not shown significant improvement in the symptoms of BPSD. Improvement for the caregivers as a result of physical exercises (walking, running, and dancing, etc.) has been demonstrated. ${ }^{53}$

\section{Touch Therapy}

It can include massage, craniosacral techniques, or therapeutic touch. It has been investigated through a three-blind fold study that the effect of touch therapy on BPSD has a significant effect in reducing behavioral symptoms when compared to the group without any touch intervention. Massage and touch therapies aim to reduce depression, anxiety, and other behavioral symptoms of dementia. ${ }^{54}$

\section{Physiotherapy}

Physiotherapy can help manage pain. Pain affects mental function, motivation, and affects how the person with dementia responds to any rehabilitation program. People living with dementia who have difficulty speaking will not be able to easily report pain. These people are at risk of receiving inadequate medication and treatment of pain. It is important that pain is addressed before and during therapy to allow for better rehabilitation. ${ }^{55}$

\section{Brief Psychotherapies for Dementia}

\section{Cognitive Behavior Therapy}

Over the past 10 years, there has been an increasing need to apply CBT-based therapies in care for dementia. There have been reported positive findings from a clinical trial of CBT with people in the early stages of Alzheimer's disease. Favorable results have been obtained with individual and group CBT. ${ }^{56}$

\section{Interpersonal Therapy}

It examines the individual's distress within an interpersonal context. It uses a specific framework in which the individual's distress is conceptualized through either of the domains: interpersonal disputes; interpersonal/personality difficulties; bereavement; and transitions/life events. Despite there being good empirical evidence of the success of this form of treatment with older people, the use of this therapy with patients of dementia is recent. ${ }^{57}$

\section{Education}

This entails paying closer attention to patients' needs especially providing basic human needs like toileting, making basic personal care items reachable to the patients/residents, identifying any early sign of distress with quick/prompt intervention, identifying any communication deficits, and addressing it. Both caregivers and families must be psychoeducated about the patient's problems and management. ${ }^{58}$

\section{Yoga and Meditation}

In a way, both yoga and meditation are "brain exercises" that engage different parts of the brain based on the components of practice (breathing, movement, postures, chanting, visualization, and concentration) and can help the brain form new connections and recover from injuries or to stimulate neuroplasticity. Yoga may play a role in prevention and improve symptoms and quality of life for patients and their caregivers alike. Studies have also found that yoga and meditation may aid socializing and feel better. Yoga and meditation may also help prevent dementia to an extent. ${ }^{59,60}$

\section{Occupational Therapy}

Tailored activities programs (TAP) are one of occupational therapies that research has found to be effective that focuses on reducing undesirable behaviors associated with dementia. The principle of TAP is the selection of activities that are specifically tailored to the patient according to his/her abilities, interests, and roles. The program also helps caregivers to develop an increased sense of self-efficacy by offering trainings to simplify activities and help them adapt for future functional declines of the patient as well as to generalize the strategies to other contexts. ${ }^{61}$

\section{Cognitive Rehabilitation for Dementia}

The impact of cognitive interventions on the BPSD is still not wellknown because most of studies have focused on improving global or specific cognitive functions. Considering the importance of the relationship between cognitive interventions and BPSD, research trials of cognitive programs have been evaluated to find a significant reduction of delusional symptoms with a large effect size; however, aberrant motor behavior increased significantly in the treatment condition when compared to the control group. ${ }^{62}$ 


\section{Group Psychotherapy Approaches}

The goals of group therapy include creation of an emotional climate of acceptance and warmth among the group members, which helps patients to learn to accept themselves and their feelings. There is frequent intervention by the therapist to help facilitate social interaction for patients whose communication ability is impaired. Group therapy allows an opportunity for patients to experience the feelings of being part of a group, to ventilate feelings, opportunity for them to reminisce about past accomplishments and give new meaning to their lives, and to create a platform for patients to achieve a sense of self by expressing personal opinions in an environment of respect and acceptance. ${ }^{63,64}$

\section{Support Groups for Caregivers of Patients with Dementia}

The basis for using support groups as a psychosocial intervention is the assumption that when individuals who have experienced a similar traumatic event gather together to share their concerns, they can cope with the stress better than on their own. Limited data from two studies suggest that support groups may be of psychological benefit to people with dementia by reducing depression and improving quality of life and self-esteem. ${ }^{64}$ The role of support groups with respect to dementia has chiefly revolved around support groups for caregivers to relatives with dementia. Recently, the notion has been expanded to include individuals with dementia themselves. Goals include grief work, achieving balance between maintaining independence and facing dependence, responding to altered interpersonal interactions, and provision of information about the disease and community resources. ${ }^{65}$

\section{Family Therapy and Couples Therapy for Dementia}

Techniques that may be utilized in relationship counseling include focusing on one issue at a time, seeing the patient and their family separately and together, utilizing relationship as a resource, role playing, balanced focus on strengths and deficits, and collaborative stance. Role playing is a very useful technique to help the person with dementia and his or her family reduce negative statements and replace it with supportive statements that indicate kindness and compassion. ${ }^{3}$ Systematic research regarding couples and family therapy for people with dementia that could guide clinical approach is lacking. ${ }^{66,67}$

\section{Dementia Rehabilitation}

Dementia can be conceptualized in terms of social disability as well as that highlights the way in which symptoms such as memory problems-and the secondary effects of these, such as loss of confidence or negative reactions from others-affect the possible way of engaging in activities and participating in society. Activity limitation and participation restriction can be tackled from two directions, community and personal perspective. From a community perspective, the focus is on reducing external barriers by expanding awareness, changing public attitudes, and creating accessible, dementia-friendly environments. From a personal perspective, the focus is on enabling people with dementia to participate in everyday life and in their families and communities, in a way that is meaningful to them. This entails rehabilitation. ${ }^{68}$

\section{Holistic Team/Liaison Approach to Dementia}

A liaison approach is ideal for the treatment of any illness, and so for dementia. The liaison approach to manage dementia involves the following professionals in team work for an ideal outcome: 69

\section{Psychiatrist}

Pharmacotherapy manages the BPSD such as aggression, irritability, screaming and laughing without reason, inappropriate sexual behaviors, hypersexuality, and other psychological symptoms (depression, anxiety, and insomnia, etc.).

\section{Psychotherapist}

Nonpharmacological therapy or psychotherapeutic intervention in the form of diverse forms of therapy, best suited to the needs of the person with dementia is provided. Therapies may be symptombased, cognitive/behavioral or broad spectrum, traditional/brief and alternative. Psychoeducation of the condition to the family members and the patient themselves is an important element. Therapists suggest various lifestyle changes to the family members in order to accommodate for the condition of the person with dementia and offer appropriate support.

\section{Occupational Therapist}

Through their academic curricula, expertise in activity analysis, and work with older people in various settings, occupational therapists address dementia as a condition that affects occupational performance. Practitioners can educate family members, concerned others, and even those in the early stages of the disease about dementia and its functional implications. Occupational therapists evaluate persons with dementia to determine their strengths, impairments, and performance areas needing intervention. Although remediation of cognitive performance is not likely, the person may demonstrate improved function through compensation or adaptation. Occupational therapy practitioners also assist care providers to help them cope with this difficult, and yet often rewarding, role.

\section{Medical/Primary Healthcare Professional}

They manage the medical illnesses such as stroke, Parkinson's disease, cerebrovascular diseases, anemia, and others that may be present as comorbid conditions. They also take care of the routine check-ups.

\section{Nutritionist}

They provide with nutritional supplements that can play an adjunctive role to medical treatment, but they play a bigger role and have a larger potential when used as a preventive tool rather than a curative one. Omega-3 fatty acids, vitamin E, vitamin B6 and $B 12$, and $C$ along with folic acid, and curcumin have been shown to play a preventive role in the development of dementia. ${ }^{70}$

\section{Physiotherapist}

They use movement of the body to help bring about physical, psychological, and social well-being. Physiotherapy plays an important role in promoting and maintaining mobility in people with dementia as well as improving their quality of life and reducing the burden of care. 


\section{Family Members}

Family members play a crucial role in managing dementia and helping in maintaining an appropriate psychosocial care for the patient.

\section{Home-based Care in Dementia-Tips for Caregivers}

Home-based care is a cost-effective model that is comfortable to the patients as they are in familiar surroundings. It includes both pharmacotherapy and nonpharmacological management. The carers should be properly educated about the clinical features of disease as caring for a person with dementia has been identified as a chronic stressor that places caregivers at risk for physical and emotional problems. ${ }^{71}$

Care for patients with dementia involves management with the caregivers who are a part of the first line of care. Apart from the traditional nonpharmacological means of management and psychoeducation, there are several simple to-do practices that one can follow to make home living and diurnal routines easy for patients with dementia. ${ }^{72}$

\section{Calendar}

A calendar must be put in the room of the person so that he/she can be routinely reminded of the day and month. The calendar can be marked to identify a special occasion or festivity. Also, calendar with single dates that can be torn off is a practical means for the person to know the date each day. ${ }^{73}$

\section{Tripod Stick and Walker}

A tripod stick for apt balance and to reduce the chance of falling is a viable option for the person with dementia. It is well-known that "falls" are common, frequent, and can be health-risking in older ages, and preventing falls is one of the crucial aspects of care. ${ }^{74}$

\section{Identity Card}

Making the person wear an identity card with personal details such as the name, address, and contact details is a good way to ensure that if, by chance, the person loses their way to home, they can get help in crisis. If required, family members should also wear identity cards with their names so that the person with dementia can recognize the names and respective people.

\section{Family Tree}

Family members can make a family tree that can repeatedly remind the person of their family members in case their memory starts to decline. It can be placed in the person's room or somewhere in the house which is most frequented by them. ${ }^{75}$

\section{Less Furniture}

It is best to ensure minimal furniture in the room of the person with dementia so that accidents can be avoided. People with dementia may not remember getting scratched or hurt by objects/furniture in the room. Less distance between bed and bathroom should be ensured for the comfort of the person of dementia which reduces chances of fall during night times. Also, help with toilet needs should be provided when required.

\section{Exercise and Walk}

People with dementia should be encouraged to walk or exercise for 30 minutes every day in order to prevent the raised risk of stroke and cardiac arrest (which increase with dementia as comorbid condition).

\section{Cognitive Engagements}

Cognitive engagements with people suffering from dementia can involve playing simple games like chess or board games with them. It can also involve cognitive exercises to rejuvenate the mind and work upon mental abilities that may have deteriorated, for example, attention. Restorative exercises like helping the person with dementia to relearn simple operations like using switches, changing channels on a television, or operating a microwave. ${ }^{76}$

\section{Simplify Communication}

While communicating with a person suffering from dementia, one must keep commands simple, one task at a time; allow extra time for a response to an asked question before repeating it; if the individual does not appear to understand, try rephrasing what is told to them; do not talk whilst the person is trying to perform a task; avoid multitasking and distractions; make sure communication problems are not due to problems with the persons sight or hearing and check that glasses and hearing aids are in good working order; use names and explain phrases where possible, such as your son, Abhay. ${ }^{77}$

\section{Fix a Routine}

Create a small daily routine for the person. Encourage them to do more tasks and motivate them for the same. Help them if they ask.

\section{Assess the Home}

The house should be assessed for any potential hazards that may likely hurt the person or make them trip/fall.

\section{Animal-assisted Therapy for Dementia}

Animal-assisted therapy is gaining popularity as part of therapy programs in residential-aged care facilities. Humans and pet dogs, birds, and cats respond to quiet interaction with a lowering of blood pressure and an increase in neurochemicals associated with relaxation and bonding. These effects may be of benefit in ameliorating BPSD. Several small studies suggest that the presence of a dog reduces aggression and agitation, as well as promoting social behavior in people with dementia. One study has shown that aquaria in dining rooms of dementia care units stimulate residents to eat more of their meals and to gain weight but is limited by the small number of facilities studied. There is preliminary evidence that robotic pets may provide pleasure and interest to people with dementia. It is important that the animal and the therapist are trained before using animal-assisted therapy for dementia. ${ }^{78-80}$

\section{Limitations OF NONPHARMACOLOGICAL Approaches}

Each therapy has its advantages and disadvantages; however, the key lies in training the caregivers, professional, and family. In fact, it is a research-oriented suggestion that the most common interventions for BPSD are not necessarily specific therapies but working with carers or nursing home staff to change the attitudes and behavior of those in their care (at a home and fundamental care level). The field of dementia care is expanding. Training, management of behavioral and psychological symptoms, follow-up sessions, and implementation of treatment programs require 
further intensive work in order to intensify the efficacy of the nonpharmacological interventions for dementia care. ${ }^{81}$

\section{Building Resilience for Dementia- Prevention for Elders}

A few suggestions for the cognitive exercises which may be woven into one's daily routine to build resilience for dementia are the following: ${ }^{82}$

- Brush your teeth with your right as well as your left hand.

- Change the day, date, month, and year in a manually operated calendar.

- Take whiff of a perfume and try to identify which perfume it is.

- Solve the newspaper crossword puzzle.

- Learn a new language by learning one word of that new language every week and using that word in a day-to-day communication.

- Play games which will enhance one's cognition (cards, chess, and carrom).

- Innovate and play some new games.

- Learn singing or learn to play a musical instrument.

- Learn cooking, taste food items, and try to recognize the ingredients.

- Indulge in mental maths while doing any calculations; minimize the use of a calculator.

- Learn to do magic tricks.

- Learn to operate a new gadget like mobile phone, computer, microwave, and washing machine.

- Learn new applications or games.

- Learn beading, knitting, painting, craft, photography, or any new skill.

- View your photo album, and recall and share the events with family and friends.

- Travel and visit new places with the help of a map.

- Indulge in destressing exercises such as laughing, relaxing, yoga, meditation, reading, and listening to music, etc.

- Socialize.

- Sleep well at least for a period of 8-10 hours per day.

- Eat chocolates and pamper your taste buds along with eating a healthy diet.

- Allow sexual expression between couples in old age when possible.

\section{Conclusion}

The field of dementia care is ever expanding and new therapies get added to those available in the management of dementia regularly. It is prudent that NPTs become an integral part of dementia management and rehabilitation programs. While this is important, one must always combine multiple approaches together as no one method fits the bill in the long-term management of dementia. There is also a need for a team approach in the management of patients with dementia with sound communication and planning between team members. Medical management must be aimed at synergizing with nonpharmacological management to enhance the long-term management and quality of life of patients with dementia.

\section{References}

1. Das SK, Pal S, Ghosal MK. Dementia: Indian scenario. Neurol India 2012;60(6):618-624. DOI: 10.4103/0028-3886.105197.
2. Rodriguez JJ, Ferri CP, Acosta $D$, et al. Prevalence of dementia in Latin America, India, and China: a population-based cross-sectional survey. Lancet 2008;372(9637):464-474. DOI: 10.1016/S0140-6736(08) 61002-8.

3. Ferri $C P$, Prince $M$, Brayne $C$, et al. Global prevalence of dementia: a Delphi consensus study. Lancet 2005;366(9503):2112-2117. DOI: 10.1016/S0140-6736(05)67889-0.

4. Blankevoort CG, Van Heuvelen MJ, Boersma F, et al. Review of effects of physical activity on strength, balance, mobility and ADL performance in elderly subjects with dementia. Dementia Geriatr Cogn Disord 2010;30(5):392-402. DOI: 10.1159/000321357.

5. ljmker T, Lamoth CJ. Gait and cognition: the relationship between gait stability and variability with executive function in persons with and without dementia. Gait Posture 2012;35(1):126-130. DOI: 10.1016/ j.gaitpost.2011.08.022.

6. Douglas S, James I, Ballard C. Non-pharmacological interventions in dementia. Adv Psychiatr Treat 2004;10(3):171-177. DOI: 10.1192/ apt.10.3.171.

7. Cummings J, Lee G, Mortsdorf T, et al. Alzheimer's disease drug development pipeline: 2017. Alzheimers Dement (N Y) 2017;3(3): 367-384. DOI: 10.1016/j.trci.2017.05.002.

8. Brodaty $\mathrm{H}$, Arasaratnam C. Meta-analysis of nonpharmacological interventions for neuropsychiatric symptoms of dementia. Am J Psychiatry 2012;169(9):946-953. DOI: 10.1176/appi.ajp.2012.11101529.

9. Livingston G, Kelly L, Lewis-Holmes E, et al. Non-pharmacological interventions for agitation in dementia: systematic review of randomised controlled trials. Br J Psychiatry 2014;205(6):436-442. DOI: 10.1192/bjp.bp.113.141119.

10. Morris RG. The cognitive neuropsychology of Alzheimer-type dementia. London: Oxford University Press; 1996.

11. Cerejeira J, Lagarto L, Mukaetova-Ladinska E. Behavioral and psychological symptoms of dementia. Front Neurol 2012;3:73. DOI: 10.3389/fneur.2012.00073.

12. Kolanowski AM, Litaker M, Buettner L. Efficacy of theory-based activities for behavioral symptoms of dementia. Nurs Res 2005;54(4):219-228. DOI: 10.1097/00006199-200507000-00003.

13. Gitlin LN, Winter L, Dennis MP, et al. Targeting and managing behavioral symptoms in individuals with dementia: a randomized trial of a nonpharmacological intervention. J Am Geriatr Soc 2010;58(8):1465-1474. DOI: 10.1111/j.1532-5415.2010.02971.x.

14. Gitlin LN, Kales HC, Lyketsos CG. Nonpharmacologic management of behavioral symptoms in dementia. JAMA 2012;308(19):2020-2029. DOI: 10.1001/jama.2012.36918.

15. Ayalon L, Gum AM, Feliciano L, et al. Effectiveness of nonpharmacological interventions for the management of neuropsychiatric symptoms in patients with dementia: a systematic review. Arch Intern Med 2006;166(20):2182-2188. DOI: 10.1001/ archinte.166.20.2182.

16. Brodaty $H$, Burns K. Nonpharmacological management of apathy in dementia: a systematic review. Am J Geriatr Psychiatry 2012;20(7):549-564. DOI: 10.1097/JGP.0b013e31822be242.

17. Ballard CG, O'Brien J, James I, et al. Dementia: management of behavioural and psychological symptoms. Nordic J Psychiatry 2003;57(2):159-160. DOI: 10.1080/08039480310001571.

18. Cohen-Mansfield J. Theoretical frameworks for behavioral problems in dementia. Alzheimer Care Today 2000;1(4):8-21.

19. Hogan DB, Bailey P, Black $S$, et al. Diagnosis and treatment of dementia: 5. Nonpharmacologic and pharmacologic therapy for mild to moderate dementia. Can Med Assoc J 2008;179(10):1019-1026. DOI: 10.1503/cmaj.081103.

20. Turner S. Behavioural symptoms of dementia in residential settings: a selective review of non-pharmacological interventions. Aging Ment Health 2005;9(2):93-104. DOI: 10.1080/13607860512331339090.

21. Kales HC, Gitlin LN, Lyketsos CG, et al. Management of neuropsychiatric symptoms of dementia in clinical settings: recommendations from a multidisciplinary expert panel. J Am Geriatr Soc 2014;62(4):762-769. DOI: 10.1111/jgs.12730. 
22. Carlson DL, Fleming KC, Smith GE, et al. Management of dementiarelated behavioral disturbances: a nonpharmacologic approach. Mayo Clin Proceed 1995;70(11):1108-1115. DOI: 10.4065/70.11.1108.

23. Seitz DP, Brisbin S, Herrmann N, et al. Efficacy and feasibility of nonpharmacological interventions for neuropsychiatric symptoms of dementia in long term care: a systematic review. J Am Med Dir Assoc 2012;13(6):503-506. DOI: 10.1016/j.jamda.2011.12.059.

24. Gitlin LN, Winter L, Dennis MP, et al. A non-pharmacological intervention to manage behavioral and psychological symptoms of dementia and reduce caregiver distress: design and methods of project ACT3. Clin Interv Aging 2007;2(4):695-703. DOI: 10.2147/cia.s1337.

25. Ballard C, Corbett A. Management of neuropsychiatric symptoms in people with dementia. CNS Drugs 2010;24(9):729-739. DOI: 10.2165/11319240-000000000-00000.

26. Deudon A, Maubourguet N, Gervais X, et al. Non-pharmacological management of behavioural symptoms in nursing homes. Int $J$ Geriatr Psychiatry 2009;24(12):1386-1395. DOI: 10.1002/gps.2275.

27. Algase DL, Beck C, Kolanowski A, et al. Need-driven dementiacompromised behavior: an alternative view of disruptive behavior. Am J Alzheimer Dis 1996;11(6):10-19. DOI: 10.1177/153331759601100603.

28. Allen-Burge R, Stevens AB, Burgio LD. Effective behavioral interventions for decreasing dementia-related challenging behavior in nursing homes. Int J Geriatr Psychiatry 1999;14(3):213-228. DOI: 10.1002/(SICI)1099-1166(199903)14:3<213::AID-GPS974>3.0.CO;2-0.

29. Spector A, Davies S, Woods B, et al. Reality orientation for dementia: a systematic review of the evidence of effectiveness from randomized controlled trials. Gerontologist 2000;40(2):206-212. DOI: 10.1093/ geront/40.2.206.

30. Spector A, Orrell M, Davies S, et al. Can reality orientation be rehabilitated? Development and piloting of an evidence-based programme of cognition-based therapies for people with dementia. Neuropsychol Rehabil 2001;11(3-4):377-397. DOI: 10.1080/09602010143000068.

31. Feil N. The validation breakthrough: Simple techniques for communicating with people with Alzheimer's-type dementia. New York: Health Professions Press; 1993.

32. Bleathman C, Morton I. Validation therapy: extracts from 20 groups with dementia sufferers. J Adv Nurs 1992;17(6):658-666. DOI: 10.1111/j.1365-2648.1992.tb01961.x.

33. Subramaniam $P$, Woods $B$. The impact of individual reminiscence therapy for people with dementia: systematic review. Exp Rev Neurotherapeut 2012;12(5):545-555. DOI: 10.1586/ern.12.35.

34. Woods B, O'Philbin L, Farrell EM, et al. Reminiscence therapy for dementia. Cochrane Database Sys Rev 2018;3:CD001120. DOI: 10.1002/14651858.CD001120.pub3.

35. Svansdottir HB, Snædal J. Music therapy in moderate and severe dementia of Alzheimer's type: a case-control study. Int Psychogeriatr 2006;18(4):613-621. DOI: 10.1017/S1041610206003206.

36. Raglio A, Bellelli G, Traficante D, et al. Efficacy of music therapy in the treatment of behavioral and psychiatric symptoms of dementia. Alzheimer Dis Assoc Disord 2008;22(2):158-162. DOI: 10.1097/ WAD.0b013e3181630b6f.

37. McDermott O, Crellin N, Ridder HM, et al. Music therapy in dementia: a narrative synthesis systematic review. Int J Geriatr Psychiatry 2013;28(8):781-794. DOI: 10.1002/gps.3895.

38. Beard RL. Art therapies and dementia care: a systematic review. Dementia 2012;11(5):633-656. DOI: 10.1177/1471301211421090.

39. Burton A. Bringing arts-based therapies in from the scientific cold. Lancet Neurol 2009;8(9):784-785. DOI: 10.1016/S1474-4422(09)70216-9.

40. Politis AM, Vozzella S, Mayer LS, et al. A randomized, controlled, clinical trial of activity therapy for apathy in patients with dementia residing in long-term care. Int J Geriatr Psychiatry 2004;19(11): 1087-1094. DOI: 10.1002/gps.1215.

41. Hokkanen L, Rantala L, Remes AM, et al. Dance/movement therapeutic methods in management of dementia. J Am Geriatr Soc 2003;51(4):576-577. DOI: 10.1046/j.1532-5415.2003.51175.x.
42. Meland B. Effects of Reiki on pain and anxiety in the elderly diagnosed with dementia: a series of case reports. Altern Ther Health Med 2009;15(4):56-57.

43. Fowler S, Newton L. Complementary and alternative therapies: the nurse's role. J Neurosci Nurs 2006;38(4):261-266. DOI: 10.1097/01376517-200608000-00009.

44. Yu J, Zhang X, Liu C, et al. Effect of acupuncture treatment on vascular dementia. Neurol Res 2006;28(1):97-103. DOI: 10.1179/016164106X91951.

45. Kwok T, Leung PC, Wing YK, et al. The effectiveness of acupuncture on the sleep quality of elderly with dementia: a within-subjects trial. Clin Interv Aging 2013;8:923-928. DOI: 10.2147/CIA.S45611.

46. Snow LA, Hovanec L, Brandt J. A controlled trial of aromatherapy for agitation in nursing home patients with dementia.J Altern Complement Med 2004;10(3):431-437. DOI: 10.1089/1075553041323696.

47. Burns $\mathrm{A}$, Allen $\mathrm{H}$, Tomenson B, et al. Bright light therapy for agitation in dementia: a randomized controlled trial. Int Psychogeriatr 2009;21(4):711-721. DOI: 10.1017/S1041610209008886.

48. Baker R, Bell S, Baker E, et al. A randomized controlled trial of the effects of multi-sensory stimulation (MSS) for people with dementia. Br J Clin Psychol 2001;40(1):81-96. DOI: 10.1348/014466501163508.

49. Zetteler J. Effectiveness of simulated presence therapy for individuals with dementia: a systematic review and meta-analysis. Aging Ment Health 2008;12(6):779-785. DOI: 10.1080/13607860802380631.

50. Cheston R, Thorne K, Whitby $P$, et al. Simulated presence therapy, attachment and separation amongst people with dementia. Dementia 2007;6(3):442-449. DOI: 10.1177/14713012070060030703.

51. Staal JA, Matheis R, Collier $L$, et al. The effects of Snoezelen (multisensory behavior therapy) and psychiatric care on agitation, apathy, and activities of daily living in dementia patients on a short term geriatric psychiatric inpatient unit. Int J Psychiatry Med 2007;37(4):357-370. DOI: 10.2190/PM.37.4.a.

52. Scherder EJ, Bouma A, Steen L. Influence of transcutaneous electrical nerve stimulation on memory in patients with dementia of the Alzheimer type. J Clin Exp Neuropsychol 1992;14(6):951-960. DOI: 10.1080/01688639208402546.

53. Heyn $\mathrm{P}$, Abreu BC, Ottenbacher KJ. The effects of exercise training on elderly persons with cognitive impairment and dementia: a meta-analysis. Arch Phys Med Rehabil 2004;85(10):1694-1704. DOI: 10.1016/j.apmr.2004.03.019.

54. Cahill S, Woods B, Droes RM, et al. Early psychosocial interventions in dementia: evidence-based practice. New York: Jessica Kingsley Publishers; 2008.

55. Shaw FE. Falls in cognitive impairment and dementia. Clin Geriatr Med 2002;18(2):159-173. DOI: 10.1016/S0749-0690(02)00003-4.

56. Sadowsky $\mathrm{CH}$, Galvin JE. Guidelines for the management of cognitive and behavioral problems in dementia. J Am Board Fam Med 2012;25(3):350-366. DOI: 10.3122/jabfm.2012.03.100183.

57. Kitwood T. Towards a theory of dementia care: the interpersonal process. Ageing Soc 1993;13(1):51-67. DOI: 10.1017/ S0144686X00000647.

58. Kasl-Godley J, Gatz M. Psychosocial interventions for individuals with dementia: an integration of theory, therapy, and a clinical understanding of dementia. Clin Psychol Rev 2000;20(6):755-782. DOI: 10.1016/S0272-7358(99)00062-8.

59. Fan JT, Chen KM. Using silver yoga exercises to promote physical and mental health of elders with dementia in long-term care facilities. Int Psychogeriatr 2011;23(8):1222-1230. DOI: 10.1017/S1041610211000287.

60. Oken BS, Fonareva I, Haas M, et al. Pilot controlled trial of mindfulness meditation and education for dementia caregivers. J Altern Complement Med 2010;16(10):1031-1038. DOI: 10.1089/ acm.2009.0733.

61. Graff MJ, Vernooij-Dassen MJ, Thijssen M, et al. Community based occupational therapy for patients with dementia and their care givers: randomised controlled trial. BMJ 2006;333(7580):1196. DOI: 10.1136/ bmj.39001.688843.BE. 
62. Clare L, Woods RT. Cognitive training and cognitive rehabilitation for people with early-stage Alzheimer's disease: a review. Neuropsychol Rehabil 2004;14(4):385-401. DOI: 10.1080/09602010443000074.

63. Brooker D, Duce L. Wellbeing and activity in dementia: a comparison of group reminiscence therapy, structured goal-directed group activity and unstructured time. Aging Ment Health 2000;4(4): 354-358. DOI: 10.1080/713649967.

64. Chien LY, Chu H, Guo JL, et al. Caregiver support groups in patients with dementia: a meta-analysis. Int J Geriatr Psychiatry 2011;26(10):1089-1098. DOI: 10.1002/gps.2660.

65. Belle SH, Burgio L, Burns R, et al. Enhancing the quality of life of dementia caregivers from different ethnic or racial groups: a randomized, controlled trial. Ann Intern Med 2006;145(10):727-738. DOI: 10.7326/0003-4819-145-10-200611210-00005.

66. Gwyther LP, Blazer DG. Family therapy and the dementia patient. Am Fam Physician 1984;29(5):149-156.

67. Brodaty H, Donkin M. Family caregivers of people with dementia. Dialog Clin Neurosci 2009;11(2):217-228.

68. Clare L. Neuropsychological rehabilitation and people with dementia. UK: Psychology Press; 2007.

69. Galvin JE, Valois L, Zweig Y. Collaborative transdisciplinary team approach for dementia care. Neurodegen Dis Manage 2014;4(6): 455-469. DOI: 10.2217/nmt.14.47.

70. Feart C, Samieri C, Rondeau V, et al. Adherence to a mediterranean diet, cognitive decline, and risk of dementia. JAMA 2009;302(6): 638-648. DOI: 10.1001/jama.2009.1146.

71. Mitchell SL, Morris JN, Park PS, et al. Terminal care for persons with advanced dementia in the nursing home and home care settings. J Palliative Med 2004;7(6):808-816. DOI: 10.1089/jpm.2004.7.808.

72. Dias A, Dewey ME, D'Souza J, et al. The effectiveness of a home care program for supporting caregivers of persons with dementia in developing countries: a randomised controlled trial from Goa, India. PloS One 2008;3(6):e2333. DOI: 10.1371/journal.pone.0002333.
73. Camp CJ, Foss JW, O'Hanlon AM, et al. Memory interventions for persons with dementia. Appl Cogn Psychol 1996;10(3):193-210. DOI: 10.1002/(SICI)1099-0720(199606)10:3<193::AID-ACP374>3.0. $\mathrm{CO} ; 2-4$.

74. Christofoletti G, Oliani MM, Gobbi S, et al. Effects of motor intervention in elderly patients with dementia: an analysis of randomized controlled trials. Topics Geriatr Rehabil 2007;23(2): 149-154. DOI: 10.1097/01.TGR.0000270183.90778.8e.

75. Zarit SH, Femia EE. A future for family care and dementia intervention research? Challenges and strategies. Aging Ment Health 2008;12(1): 5-13. DOI: 10.1080/13607860701616317.

76. Yu F, Rose KM, Burgener SC, et al. Cognitive training for early-stage Alzheimer's disease and dementia. J Gerontol Nurs 2009;35(3):23-29. DOI: 10.3928/00989134-20090301-10.

77. Adams T, Gardiner P.Communication and interaction within dementia care triads: developing a theory for relationship-centred care. Dementia 2005;4(2):185-205. DOI: 10.1177/1471301205051092.

78. Filan SL, Llewellyn-Jones RH. Animal-assisted therapy for dementia: a review of the literature. Int Psychogeriatr 2006;18(4):597-611. DOI: 10.1017/S1041610206003322.

79. Motomura N, Yagi T, Ohyama H. Animal assisted therapy for people with dementia. Psychogeriatrics 2004;4(2):40-42. DOI: 10.1111/j.14798301.2004.00062.x.

80. Perkins J, Bartlett $H$, Travers $C$, et al. Dog-assisted therapy for older people with dementia: A review. Australasian J Ageing 2008;27(4): 177-182. DOI: 10.1111/j.1741-6612.2008.00317.x.

81. Khan F, Curtice M. Non-pharmacological management of behavioural symptoms of dementia. Br J Commun Nurs 2011;16(9):441-449. DOI: 10.12968/bjcn.2011.16.9.441.

82. Cabrera E, Sutcliffe C, Verbeek H, et al. Non-pharmacological interventions as a best practice strategy in people with dementia living in nursing homes. A systematic review. Eur Geriatr Med 2015;6(2):134-150. DOI: 10.1016/j.eurger.2014.06.003. 